\title{
Use of phase change materials in concrete: current challenges
}

\author{
Adeyemi Adesina* \\ Concordia University, Montreal, Canada
}

Received: 6 June 2019 / Accepted: 19 July 2019

\begin{abstract}
Sustainability awareness in the building industry has increased in recent years, and several initiatives have been developed. One of the areas gaining attention recently is the application of phase change materials (PCMs) in concrete. PCMs are materials capable of storing and releasing energy based on the temperature of the environment in which they are situated. This capability makes them provide heat during cold times, and absorb heat when the temperature is higher. As concrete is the most used building material in the world, the use of PCMs in concrete will be a great way to widen the application of PCMs. However, as the composition of concrete determines its properties; hence, the use of PCM in concrete can be detrimental to the properties of concrete. Some of the negative effects on the properties of concrete include reduced mechanical properties and corrosion of reinforcements. In addition, PCMs suitable for concrete are not readily available in the market, and extremely expensive when available. Also, lack of long-term data on the effect of PCM on concrete's durability has discouraged stakeholders to accept the use of PCMs in concrete. This paper explored the current challenges faced by the application of PCMs in concrete which, and possible opportunities that will open more pathway for extensive research and applications of PCM in concrete. It was concluded that the use of right type and proportion of PCM in concrete can result in similar strength to those of control samples. Also, certain methods of incorporating PCMs into the concrete were found to be more effective. Therefore, it is imperative that building engineers carry out initial tests to determine the most appropriate incorporation method to be used. Finally, huge energy savings can be achieved through the use of PCM in concrete without any significant reduction in mechanical strength.
\end{abstract}

\section{Introduction}

Building energy consumptions accounts for over one-third of the energy consumption in most countries. And implementing sustainability concepts in today's construction has become the target of building industry. Hence, a lot of effort has been directed to reducing building energy consumption. Several methods have been proposed to reduce the operational energy of buildings, and one of the promising ways is the incorporation of phase change materials in building materials. Phase change material can store and release energy at specific temperature ranges. Hence, incorporating PCM in concrete; which is the most used building material in the world can help in reducing energy consumption for buildings made with such concrete. Several uses of PCMs already exist in building materials, such as in drop ceilings, metal roofs and stud walls. These applications have been used to save energy, create more efficient HVAC systems, and provide the occupants in a building with great comfort.

\footnotetext{
* e-mail: a_adesin@encs. concordia.ca
}

Though most of the work done on the incorporation of PCM into building material is common in plasters and wall boards $[1,2]$. The past 25 years have seen the incorporation of PCMs in concrete to conserve building energy consumptions, and several developments have been made. Thermal mass which is a characteristic of importance for materials used in building construction indicates the ability of the building material to absorb, store and release energy at a future time. As concrete has a higher thermal energy compared to other building materials [3], this property enables it to have a high energy saving advantage compared to other building materials. Therefore, being able to use concrete as a carrier for PCMs will lead to an increase in the thermal mass of the concrete, and this can be used to conserve more energy during the off-peak period. Computer simulations made by Farid and Chen [4], to observe the effect of PCM in concrete floors when heated constantly for 8 hours electrically during off-peak. They observed after the heating was switched off, the floor without PCM layer lost most of the stored it within little time, while the floors with PCM could provide heat for the rest of the day. In addition, concrete floor with PCM 
Table 1. Types and properties of PCMs.

\begin{tabular}{lll}
\hline Types of PCMs & Benefits & Limitations \\
\hline Organic & i. Excellent freezing and melting properties & i. Very expensive \\
& ii. High latent heat storage & ii. Large volume change \\
& iii. Low volume change & \\
& iv. Inflammable & \\
v. Chemically Stable & \\
& vi. Does not super cool & \\
& vii. Non-corrosive & \\
viii. Non-toxic & \\
i. Cheap & i. High volume change \\
Inorganic & ii. Readily available & ii. Supercooling \\
& iii. Non-flammable & iii. Degradation \\
& iv. High heat of fusion & iv. Corrosive to most metals \\
& v. Good thermal conductivity & \\
i. High volume storage density & i. Less explored \\
Eutectics & ii. Sharp melting temperature & \\
\hline
\end{tabular}

has lower fluctuation in surface temperature, compared to those without PCM.

Despite the sustainable advantage of using PCM in concrete, its incorporation can result in detrimental effects on both its fresh and hardened properties. The method of incorporation and the type of PCM used are one of the main factors that affect the resulting effect on its properties. Therefore, in order to encourage more research and development in the use of PCM in concrete to create sustainable and resilient infrastructures, this paper discusses briefly the current challenges faced by this technology alongside opportunities. It is anticipated that this paper will drive more need to develop more ways to reduce building energy consumption. Also, this paper will serve as a reference for scientist, engineers and contractors looking for ways to incorporate PCMs into concrete and other building materials.

\subsection{Phase change materials}

Phase change materials also referred to as latent heat storage materials (LHSMs), are materials that can absorb or liberate energy in terms of heat at certain temperatures [5]. As the material absorbs or liberates heat, there is a change in the physical state of the material from either solid to liquid or vice versa. A common example of PCM is water which as the ability to change from solid (i.e. ice) to liquid, and liquid to solid; thereby releasing and storing energy in the process of its phase changes. Generally, an ideal PCM to be used for storage of thermal energy should undergo small volume changes, non-toxic, non-corrosive, possess high thermal conductivity and specific heat capacity, and must not super cool or decompose [6]. The types of PCM available are listed in Table 1, alongside their benefits and limitations.

\subsection{PCM heat exchange mechanism}

When PCMs are exposed to a heat source, there is a physical change in the PCM from solid to liquid as a result of chemical bonds within the PCMs breaking. This breaking of bonds leads to absorption of heat (i.e. an endothermic process). As the PCM absorbs more heat, the chemical bonds continue to break until the phase change temperature of the PCM is reached and the temperature stays constant until the bond breaking is complete (i.e. until the melting process is finished). The heat stored or absorbed by the PCM during the phase change process is referred to as latent heat.

When the temperature of the source is below the phase change temperature of the PCM, the molten PCM begins to change in state. As the PCM solidifies, there's a release of heat energy into the environment. The heat stored and released during the phase change process is referred to as latent heat. It should however be noted that there is a difference between latent heat and sensible heat. Latent heat is the associated with the change in temperature and change in state of a material, while sensible heat is the associated with the change in temperature of a material but not change in state. Latent heat has an advantage over sensible heat because of its ability to store a large amount of heat, with only little change in temperature. Garg et al. [7] and Hasnain [8] observed that latent heat storage of a material is about 5 to 10 times that of sensible heat storage.

\subsection{Method of PCMs incorporation into concrete}

There are 3 main ways to incorporate PCMs into concrete, and it can be classified into direct, impregnation, and immersion methods. Powdered or granular PCMs can be applied directly when mixing concrete's components (i.e. cement, water and aggregates). The PCMs are introduced at the end of the dry mix process and has been found out to increase the concrete's plasticity [9]. However, before the PCMs are added to the concrete mixture; they must first be enclosed in a capsule. This method is known as the direct method. The process of containment of PCMs into capsules is called encapsulation, and it is important so as to prevent the PCMs from the harsh high alkali environment of concrete. In addition, encapsulation is paramount to allow 
Table 2. Estimated energy storage properties of building materials of $20 \mathrm{~cm}$ thickness.

\begin{tabular}{lllll}
\hline Materials & \multicolumn{3}{c}{ Material properties } \\
\cline { 2 - 5 } & Density $\left(\mathrm{kg} / \mathrm{m}^{3}\right)$ & Thermal conductivity $(\mathrm{W} /(\mathrm{m} \mathrm{K})$ & \multicolumn{2}{c}{ Thermal capacity $\left(\mathrm{KJ} / \mathrm{m}^{2} \mathrm{~K}\right)$} \\
\cline { 3 - 5 } & & & Overall & In relation to Gypsum board \\
\hline Concrete & 2400 & 1.70 & 360.00 & 10.32 \\
Gypsum board & 160 & 0.17 & 34.88 & 1.00 \\
Plasterboard & 160 & 0.17 & 28.80 & 0.83 \\
Plasters & 850 & 0.20 & 170 & 4.87 \\
\hline
\end{tabular}

less interaction with the cement hydration process. Two types of encapsulation exist namely microencapsulation and macroencapsulation. Microencapsulation involves containment of PCMs in small capsules made with a thin layer of high weight polymer [6]. And macroencapsulation containment of PCMs is in packets like panels, pouches, or tubes. Microencapsulation is more effective than macroencapusulation because it allows the PCMs to be incorporated easily and in a cheap way into construction materials [10]. In addition, microencapsulated PCMs allow effective heat transfer because of its small size compared to macroencapsulated PCMs. Also, the solidification of macroencapsuated PCMs around the edges of its containment makes it transfer heat ineffectively [6]. However, the encapsulation process is expensive, but its economical on the long run as this encapsulation prevents the PCMs from getting in contact with the concrete thereby not affecting its strength negatively.

PCM can also be incorporated into concrete using impregnation technique which can be carried out by first drying the aggregate at a specific temperature, to remove the moisture in the porous aggregate. Then the aggregates are soaked in the desired melted solution of PCM for a minimum of 24 hours to allow the pores of the aggregates to be saturated with the PCM. Immersion method entails soaking of porous concrete products in molten PCM in a similar way as the impregnation method. Factors such as the type of PCM used, the temperature of the PCM when immersion was done has been found to the effectiveness of this method and the absorption capacity of the concrete being immersed. Hawes and Feldman [11] concluded that compared to normal concrete blocks, autoclaved concrete blocks are more appropriate for immersion because of its higher porosity and absorption. The method of incorporation of $\mathrm{PCM}$ into concrete affects its fresh and mechanical properties [12]. Cabeza et al. [13] observed that using the immersion method to incorporate PCM into concrete gives a compressive strength above $25 \mathrm{MPa}$ and a tensile strength above $6 \mathrm{MPa}$ at 28 days. However, Hunger et al. [14] recorded a significant reduction in compressive strength when direct mixing method was used to incorporate PCM into self-compacting concrete (SCC). The trend in compressive strength reduction continued with an increase in the amount of PCM incorporated into the SCC. Reduction in strength with the use of direct mixing method can be attributed to possible leakage of $\mathrm{PCM}$ from the containment during mixing. Also, a huge difference in the strength of the containment (i.e. capsules) and other components of concrete can be responsible for the strength loss [15]. Lee et al. [16] used the impregnation method to incorporate PCM into the concrete until a required absorption rate of $3.9-6.8 \%$ was achieved. It was observed from the study, that the impregnated concrete blocks can store the sensible heat of the concrete as well as the sensible and latent heat of the impregnated PCM.

\section{The concrete's advantage}

Several properties of concrete make it as a suitable carrier for PCM. Some of the thermal properties that give concrete an edge as an effective carrier over other building materials are briefly discussed.

\subsection{Thermal conductivity}

The thermal conductivity of a material is the rate at which heat can flow through the material. As it can be observed from Table 2, concrete has a thermal conductivity of $1.70 \mathrm{~W} / \mathrm{m} \mathrm{k}$ which is higher compared to other building materials. This shows that during the phase change of PCMs incorporated into these materials, the concrete will be able to allow more absorption and release of heat energy compared to other materials.

\subsection{Density}

The density of conventional concrete is higher compared to other building materials in which PCM has been incorporated. This higher density will allow the concrete to have higher thermal capacity when incorporated with PCMs, compared to other building materials in which PCM can be incorporated. The higher density of concrete also makes it have a higher sensible heat storage. Figure 1 shows the relationship between the density and storage capacity of some constructional building material, it will be observed that the storage capacity increases with the density of the materials.

\subsection{Thermal mass}

Thermal mass is a characteristic of materials which permits the building material to absorb, store and release 


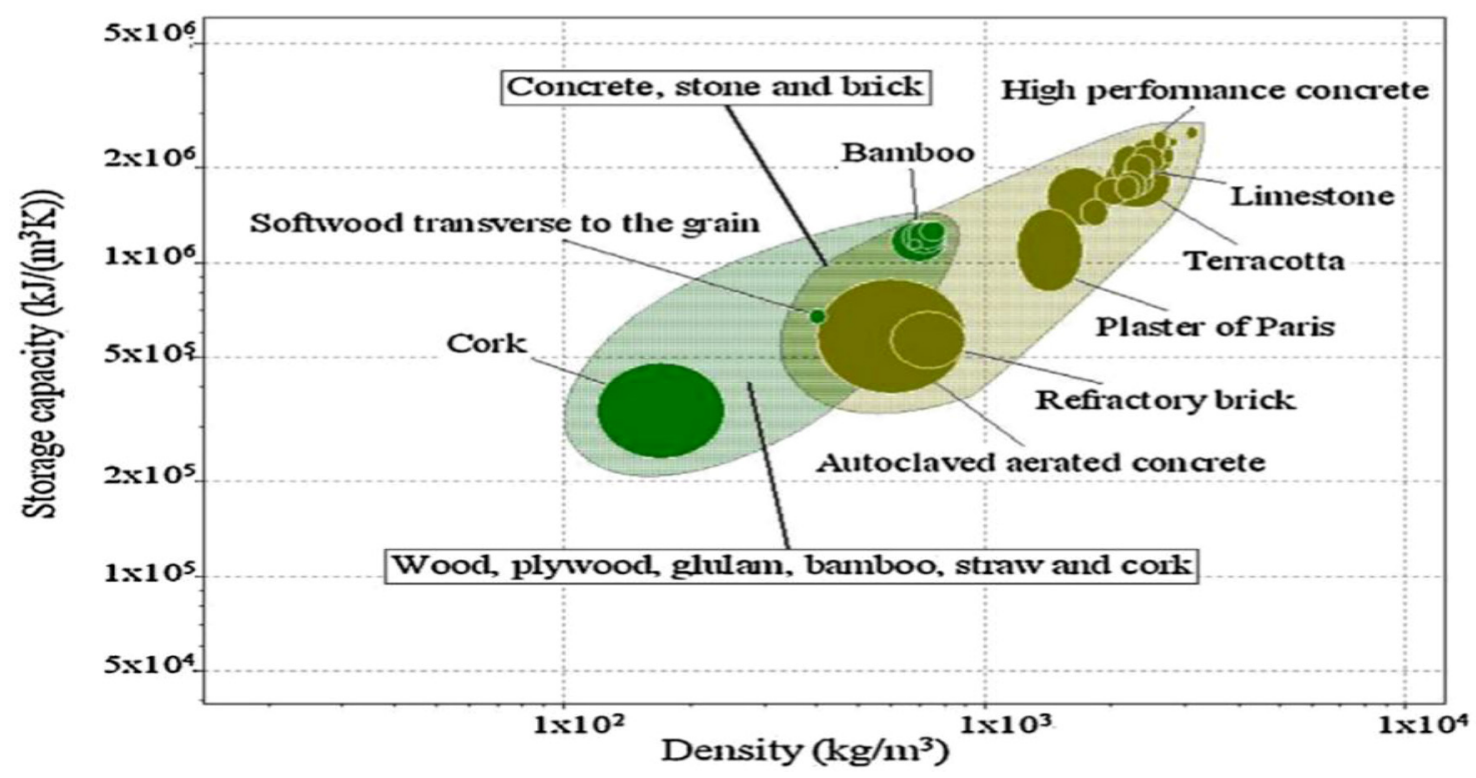

Fig. 1. Relationship between density and storage capacity of some building material [17].

energy later. Concrete high thermal mass enables it to have a high-energy saving advantage compared to other building materials. Incorporation of PCM into concrete would help in increasing its thermal mass and consequently shift the demand for energy during the off-peak period. Baetens [3] also observed that the thermal mass of concrete was greatly enhanced with the addition of PCMs compared to other building materials incorporating PCM.

\section{Current challenges with the use of PCM in concrete}

Despite the sustainability advantages to be achieved with the incorporation of PCMs in concrete, several challenges are being encountered which hinders its universal acceptance and large-scale applications. Some of the major challenges are further discussed, and possible solutions presented in Table 3 .

\subsection{Ineffective phase change properties}

This occurs as a result of supercooling as the PCMs can go through an effective phase change as a result of segregation and inability to solidify back leading to a reduction in the ability of the PCM to store latent heat and an incomplete phase change cycle. Supercooling of PCMs occurs because the phase change of some PCMs that does not melt consistently lead to segregation of the PCM. This phenomenon affects the thermal characteristics of the PCM which leads to inconsistent phase change cycle. The inconsistent cycles are as a result of the chemicals in some of these PCMs being separated when in a liquid state and unable to solidify back properly.

\subsection{Concrete's alkali environment}

As concrete's internal environment is very alkali in nature, this high alkali in some cases leads to the decay of the PCM [15]. Therefore, it has been suggested to use the paraffin wax PCM as it is not reactive in an alkali environment, also other PCMs with low alkalinity can be used. High alkali PCM such as polyethylene glycol (PEG) should be avoided for use in concrete. This precaution is needed to be taken mostly in concrete's products such as concrete blocks which are highly porous and have a high probability of getting an external supply of alkali [18]. Hawes [18] also suggested that the use of appropriate pozzolans at a specific control level will help to reduce the concrete's alkalinity. But the application has to be done carefully as pozzolans reduce porosity. However, a certain amount of porosity is required for the incorporated PCM in concrete to absorb and release energy in terms of heat. It is worth to mention that the alkalinity of concrete's pore solution has to be high to a certain level, especially in reinforced concrete so as to prevent corrosion of the reinforcement.

\subsection{Leakage of PCM}

As mentioned earlier, the leakage of PCM from concrete can occur when the method of incorporation of PCM into concrete is by immersion method or the direct mixing method. For the immersion method, leakage is possible as a result of the concrete members such as concrete block being very dense and unable to absorb the PCM efficiently. This results in more $\mathrm{PCM}$ at the outer part of the block, and as phase change occurs (i.e. melting of the PCM) the PCM at the outer part of the block tends to leak out. Also, leakage can also occur when the incorporation of PCM is carried out using the direct mixing method. Leakage, in this case, is 
Table 3. Possible solutions to current challenges faced by the use of PCM in concrete.

\begin{tabular}{|c|c|}
\hline Problems & Possible solutions \\
\hline Loss of strength & $\begin{array}{l}\text { i. Use of the appropriate method of PCM incorporation into concrete } \\
\text { ii. Encapsulation of PCM to avoid contact with concrete alkali environment } \\
\text { iii. Encapsulation of PCM in irregular shapes instead of the current spheres } \\
\text { and capsules }\end{array}$ \\
\hline Flammability & $\begin{array}{l}\text { i. Use of non-flammable PCMs } \\
\text { ii. Addition of fire retardant admixtures }\end{array}$ \\
\hline Ineffective phase change & $\begin{array}{l}\text { i. The packaging of PCM in shallow or thin containers } \\
\text { ii. Use of PCMs that do not super cool } \\
\text { iii. Using appropriate incorporation method to ensure that the PCMs are } \\
\text { effectively incorporated and would work efficiently } \\
\text { iv. Using PCMs that have a phase change temperature of the required application } \\
\text { e.g. PCM to be used in concrete for building construction should give a human } \\
\text { comfort temperature }\left(20-28^{\circ} \mathrm{C}\right) \\
\text { v. Addition of admixtures that enhances thermal conductivity }\end{array}$ \\
\hline High volume change & $\begin{array}{l}\text { i. Use of PCMs in the required temperature range of application } \\
\text { ii. Use of inorganic PCMs when necessary }\end{array}$ \\
\hline Leakage of PCM & $\begin{array}{l}\text { i. Using appropriate mixing method } \\
\text { ii. Encapsulation of PCMs }\end{array}$ \\
\hline Super cooling & i. Development of an ideal and effective storage system for salt hydrates \\
\hline Corrosion of steel reinforcement & i. Encapsulation of PCMs \\
\hline
\end{tabular}

as a result of the breaking of some of the encapsulated PCM during its mechanical mixing with other components in concrete.

\subsection{Application methods}

The method of incorporation of PCM into concrete has been found to influence the general mechanical and thermal properties of concrete. Therefore, careful analysis must be done to select the best method of incorporation of PCM into concrete so as to obtain an effective phase change of the PCMs while maintaining the optimum strength of the concrete. For example, optimum results will be achieved if a concrete block is immersed in molten PCM rather than if a non-porous aggregate impregnated with PCM before its using it to make the concrete block. Lee et al. [16] used the impregnation method to incorporate PCM into the concrete until a required absorption rate of $3.9-6.8 \%$ was achieved. It was observed from the study, that the impregnated concrete blocks can store the sensible heat of the concrete as well as the sensible and latent heat of the impregnated PCM.

\subsection{Long-term stability and flammability}

So far, the long-term effects of PCMs have not been established and there is a possibility for some of the PCM to degrade after a certain number of cycles. Also, aspects such as the occurrence of fire with the use of organic PCM, and durability of concrete made with PCM has not been fully explored. The flammability of some of the PCMs might pose a serious threat when the concrete incorporated with PCM is exposed to fire. In addition, there is a possibility of fume discharge with the concrete exposure to fire [17].

\subsection{Cost of PCMs}

Incorporation of any new material into the concrete will increase the overall cost of the concrete. In the case of PCM incorporation into concrete, the cost of PCM and incorporation technique used will increase the cost of the concrete. As there is a limited application of PCM in concrete, the current available PCMs are expensive, and they are few types specifically made for incorporation into concrete.

\section{Recommendations and conclusion}

This paper shows the current challenges faced by the use of PCM in concrete and its possible solutions and opportunities. Based on this overview, the following conclusions can be drawn:

- Incorporation of PCM into building materials such as concrete will help in reducing significantly the building energy consumption. However, PCM used in concrete should be stable for the entire life of the concrete, not pose any fire threat, nor toxic to living organisms and its environment. In addition, the PCMs should have a phase transition temperature that is desirable for human comfort $\left(\sim 20^{\circ} \mathrm{C}\right)$.

- Use of Inorganic PCM especially hydrated salt should not be used in concrete because of the possibility of degradation after few cycles, high volume change, supercooling, and reaction with the alkali environment of concrete which make the phase change ineffective.

- Immersion method of incorporating PCM in concrete should be used when the concrete element is porous and able to absorb the molten PCM. Direct mixing of 
encapsulated PCM with concrete's component should be used when the immersion method and impregnation method cannot be used. And the impregnation method should be used when a porous aggregate is to be used in a concrete mix.

- Most of the research related to the use of PCM in concrete has been done for indoor applications to conserve heat, but there's a possibility to have an outdoor application in concrete in terms of control of heat of hydration of cement, prevent early age thermal cracking in concrete, snow melting in rigid pavement, harvesting of solar energy on concrete pavement, etc.

- Overall, most of the limitations of the use of PCM in concrete can be overcome if the right type of PCM and the right incorporation technique is employed. Also, any PCM incorporated into concrete should not alter the chemical reaction inside concrete change.

\section{References}

1. F. Kuznik, J. Virgone, J. Noel, Optimization of a phase change material wallboard for building use, Appl. Therm. Eng. 28, 1291-1298 (2008)

2. K. Ismail, J. Castro, PCM thermal insulation in buildings, Int. J. Energy Res. 21, 1281-1296 (1997)

3. R. Baetens, B. Jelle, A. Gustavsend, Phase change materials for building applications: a state-of-the-art review, Energy Build 42, 1361-1368 (2010)

4. M. Farid, X. Chen, Domestic electric space heating with heat storage, Proc. Inst. Mech. Eng. 213, 83-92 (1999)

5. A. Regin, S. Solanki, J. Saini, Heat transfer characteristics of thermal energy storage system using PCM capsules: a review, Renew. Sust. Energy Rev. 12, 2438-2458 (2008)

6. M. Amar, M. Mohamed, A review on energy conservation in building applications with thermal storage by latent heat using phase change materials, Energy Convers. Manag. 45, 263-275 (2004)

7. H. Garg, S. Mullick, A. Bhargava, Solar Thermal Energy Storage (D. Reidel Publishing Co, Dordrecht, Holland, 1985)

8. S. Hasnain, Review on sustainable thermal energy storage technologies, Part I: heat storage materials and techniques, Energy Convers. Manag. 39, 1127-1138 (1998)

9. D. Hawes, D. Banu, D. Feldman, Latent heat storage in concrete II, Solar Energy Mater. 21, 61-80 (1990)

10. Fraunhofer Institute for Solar Energy Systems ISE, Freiburg/Germany, 2002

11. D. Hawes, D. Feldman, Absorption of phase change materials in concrete, Solar Energy Mater. Solar Cells 27, 91-101 (1992)

12. L. Cabeza, M. Medrano, C. Castellón, A. Castell, J. Roca, Thermal energy storage with phase change materials in building envelopes, Contrib. Sci. 3, 501-510 (2007)

13. L. Cabeza, C. Castellón, M. Nogués, M. Medrano, R. Leppers, O. Zubillaga, Use of microencapsulated PCM in concrete walls for energy savings, Energy Build. 39, 113-119 (2007)

14. M. Hunger, A. Entrop, I. Mandilaras, H. Brouwers, M. Founti, The behavior of self-compacting concrete containing micro-encapsulated phase change materials, Cement Concr. Compos. 31, 731-743 (2009)

15. L. Tung-Chai, P. Chi-Sun, Use of phase change materials for thermal energy storage in concrete: an overview, Constr. Build. Mater. 46, 55-62 (2013)

16. T. Lee, D. Hawes, D. Banu, Feldman, Control aspects of latent heat storage and recovery in concrete, Solar Energy Mater. Solar Cells 62, 217-237 (2000)

17. A. Jeanjean, R. Olives, X. Py, Selection criteria of thermal mass materials for low-energy building construction applied to conventional and alternative materials, Energy Build. 63, 36-48 (2013)

18. D. Hawes, Latent Heat Storage, Ph.D. Thesis, Concordia University, 1991, p. 79

Cite this article as: Adeyemi Adesina, Use of phase change materials in concrete: current challenges, Renew. Energy Environ. Sustain. 4, 9 (2019) 